\title{
Emotion-based learning: insights from the lowa Gambling Task
}

\section{Oliver H. TurnbulI*, Caroline H. Bowman, Shanti Shanker and Julie L. Davies}

School of Psychology, Bangor University, Bangor, UK

\section{Edited by:}

Yao-Chu Chiu, Soochow University,

Taiwan

\section{Reviewed by:}

Masataka Watanabe, Tokyo

Metropolitan Organization for Medical

Research, Japan

Varsha Singh, Indian Institute of

Technology Delhi, India

\section{*Correspondence:}

Oliver H. Turnbull, School of Psychology, Bangor University, Bangor, LL57 2AS Wales, UK e-mail: o.turnbull@bangor.ac.uk
Interest in the cognitive and/or emotional basis of complex decision-making, and the related phenomenon of emotion-based learning, has been heavily influenced by the lowa Gambling Task. A number of psychological variables have been investigated as potentially important in understanding emotion-based learning. This paper reviews the extent to which humans are explicitly aware of how we make such decisions; the biasing influence of pre-existing emotional labels; and the extent to which emotion-based systems are anatomically and functionally independent of episodic memory. Review of literature suggests that (i) an aspect of conscious awareness does appear to be readily achieved during the IGT, but as a relatively unfocused emotion-based "gut-feeling," akin to intuition; (ii) Several studies have manipulated the affective pre-loading of IGT tasks, and make it clear that such labeling has a substantial influence on performance, an experimental manipulation similar to the phenomenon of prejudice. (iii) Finally, it appears that complex emotion-based learning can remain intact despite profound amnesia, at least in some neurological patients, a finding with a range of potentially important clinical implications: in the management of dementia; in explaining infantile amnesia; and in understanding of the possible mechanisms of psychotherapy.

\section{Keywords: emotion-based learning, intuition, prejudice, psychotherapy, episodic-memory}

\section{INTRODUCTION}

Over the last few decades, there has been a growing interest in the cognitive and/or emotional basis of complex decision-making (e.g., Bechara et al., 1994; Damasio et al., 1996; Rogers et al., 1999; Manes et al., 2002; Turnbull et al., 2003; Bowman et al., 2005; Peatfield et al., 2012). This interest was, in large part, inspired by the well-established finding that neurological patients with lesions to ventromesial (VM) frontal lobes often showed normal intelligence, with near or near-to-normal performance on a range of "executive" tasks (e.g., Bechara et al., 2000b). However, in spite of these domains of preservation, such individuals often displayed difficulties in learning from past mistakes, with real life manifestations such as entering repeatedly into inappropriate relationships, and unsuitable business agreements. Such decisions may immediately seem rewarding, but typically prove to be counter-productive in the long run, often leading to career termination and financial losses (Damasio et al., 1991; Bechara et al., 2000a). Notably, such individuals display failures in using emotional feedback from previous situations (i.e., the punishing consequences of impulsive actions) in the guidance of their future choices.

Measuring these decision-making failures in the real-world is challenging, both ethically and methodologically. The Iowa Gambling Task (IGT) was developed as a simple neuropsychological tool to tap into such deficits in emotional-processing, which might be associated with complex decision-making difficulties, as observed in individuals with frontal lobe lesions (Rolls et al., 1994; Damasio et al., 1996; Lezak et al., 2012). In a poetic turn of phrase, patients with VM lesions were argued to have "myopia for the future" (p. 217), where their focus was on the immediate outcome of decisions, with an apparent indifference to the longterm consequences of their actions (Bechara et al., 1994; Bechara, 2005).

A key element of the recent complex decision-making literature has been the role of emotion (Bechara et al., 1994; Damasio et al., 1996; Rogers etal., 1999; Manes etal., 2002), and indeed its ability to drive emotion-based learning (EBL) during complex decision-making (Damasio et al., 1996; LeDoux, 1996, 2000; Turnbull et al., 2003, 2006). EBL systems are known to facilitate insights about the possible outcome of complex decisions, based on prior experience of the emotional consequences of actions, with particular objects and/or agents (Claparède, 1951; Johnson et al., 1985; Tranel and Damasio, 1993; Bechara etal., 1994; Damasio et al., 1996; Rogers et al., 1999; LeDoux, 2000). The role of emotion in such decision-making is supported by studies of patients with VM frontal, amygdala, and insular lesions (e.g., Bechara et al., 1997, 1999, 2003; Clark et al., 2008), as well as studies measuring skinconductance changes (e.g., Bechara et al., 1996, 1997, 1999; see also Suzuki et al., 2003). Importantly, (see below) this class of memory (or learning) appears to be independent of the episodic memory systems of the medial temporal lobe (Claparède, 1951; Tulving and Schacter, 1990; Turnbull and Evans, 2006; Evans-Roberts and Turnbull, 2011).

\section{THE IOWA GAMBLING TASK}

The IGT (Bechara etal., 1994) has become the key experimental paradigm in evaluation of emotion-based decision-making, especially when humans are faced with emotion-mediated information, ambiguous contingencies, and uncertain consequences 
(e.g., Rogers et al., 1999; Manes et al., 2002; Bowman and Turnbull, 2004; Happaney et al., 2004). The IGT has been extraordinarily influential, with Bechara et al.'s (1994) original paper having already acquired over 3000 citations on a Google Scholar search for this paper (November 2013). The spread of influence is also remarkably diverse, spanning a range of theoretical, and clinical papers in psychiatry (e.g., Cavedini et al., 2002; Evans et al., 2005; Must et al., 2006), psychology (e.g., Schmitt et al., 1999; Blair et al., 2001), neuropsychology (Turnbull and Evans, 2006; Torralva et al., 2007), and neurology (e.g., Bechara et al., 1999; North and O'Carroll, 2001; Cavedini et al., 2002; Anderson et al., 2006).

A number of psychological variables have been investigated as potentially important in understanding the nature of these EBL systems. The most prominent of these are (i) the extent to which we are explicitly aware of the basis of such decisions; (ii) the biasing influence of pre-existing emotional labels in complex decision making; and (iii) the extent to which EBL systems are anatomically and functionally independent of episodic memory systems. Each of these issues are briefly reviewed in this article.

\section{DECISION-MAKING OUTSIDE AWARENESS}

An important element in our understanding of the nature of emotion-based-learning, and the factors that drive learning on the IGT in particular, is the question of conscious awareness. The Iowa group have argued that the IGT is extremely complex in nature (Damasio, 1994, pp. 205-222), and that participants do not appear to explicitly understand the contingencies of the game (Bechara et al., 1994, 1996, 1997, 2000b). In analyzing this issue, it is important to keep in mind the definition of "awareness" used by the original Iowa group (e.g., Bechara et al., 1997) - an issue which may explain some of the emergent controversies amongst IGT researchers.

Bechara et al. (1997) explored how participants "conceptualized" the task, by which they appear to have meant the broad understanding of the contingency values on the IGT, and the types of (explicit) strategies used on the task. In their study, they asked participants (patients with VM lesions and neurologically normal controls) two questions: "(i) Tell me all know about what is going on in this game? (ii) Tell me how you feel about the game" (Bechara et al., 1997, p. 1293). In other words, they sought a definition of "awareness" which emphasized formal but also general (and, arguably, rational or cognitive) understanding, as well as broadly based feelings about the task. An initial phase of task awareness was labeled as the "hunch" period, where neurotypical participants experienced conscious, but poorly formed impressions about the task (Bechara et al., 1997). During this period, neurotypical participants reported "liking" or "disliking" certain decks, often guessing the general contingencies of the decks. During a later phase of the task, most neurotypicals reached a "conceptual" period developing a better awareness of the rewarding nature of the decks. Notably, after encountering losses on specific decks, (neurotypical) participants developed pre-decision anticipatory skin conductance responses (SCRs). While, neurological patients did not generate these anticipatory SCRs, nor did they tend to enter the "hunch" period. In the later periods most neurological patients were unable to shift their pattern of choice away from the "bad" decks though many did develop a conceptual awareness. However, Bechara et al. (2000a, p. 301) reported some instances of the famous "knowing versus doing" dissociation, (first noted by Teuber, 1964) where "... patients "say" the right thing but "do" the wrong thing". Even more paradoxically, they reported that some neurotypical participants did not reach the conceptual period in that they did not describe an awareness regarding which decks were good and which were bad, yet they still made increasingly advantageous choices over time (Bechara et al., 1996, 1997).

In sum, they appear to suggest that conscious awareness on the task, and good performance are unrelated. The Iowa group explained the "unconscious" (unaware) nature of these decisions in terms of the somatic marker hypothesis (SMH; Damasio, 1989a,b, 1994; Damasio et al., 1991, pp. 205-222; Bechara et al., 2000a), where "bodily" (i.e., extra-cerebral) systems play a role in facilitating decisions (Bechara et al., 1997). This proposition has received some experimental support (Bechara et al., 2000a), but it has also attracted criticism (Tomb et al., 2002; see Dunn et al., 2006 for a review).

Further support for advantageous decision-making occurring outside of explicit awareness, might be argued to come from the "BLINK" task (Peatfield et al., 2012). An analog of the classic IGT, BLINK is some 25 times faster to complete than the conventional computerized IGT (Bechara et al., 1999). Here, individual decisions are presumably so rapid that little opportunity arises for conscious awareness to develop, thus meeting the criteria for "fast and frugal" decision-making (Gigerenzer, 2004). Notably, in spite of the rapid response rate on the BLINK paradigm, participants show IGT-like performance (see Peatfield et al., 2012 for a detailed discussion of BLINK).

In recent years, Bechara's claim of advantageous decisionmaking outside of awareness has been shaped by a series of papers which suggest that some forms of conscious awareness are available to participants on the IGT. The first of these more formal investigations was reported in Maia and McClelland's (2004) study, based on a structured questionnaire that assessed participants' knowledge of the IGT. Maia and McClelland probed the general awareness of task contingencies, without asking participants to specify the cognitive details underlying their understanding. Importantly, most participants who made advantageous choices, and thus showed preference for one or more of the decks, also demonstrated conscious feelings about the decks. Indeed, by the end of Block 1 (i.e., 20 card selections made) participants were able to report basic affective properties of decks, and by 50 card selections, the majority of participants could correctly report "good" decks. Such understanding would readily correspond to participants' decision preference (see Maia and McClelland, 2004).

Their results suggested that when behaving advantageously, participants not only had access to some explicit knowledge about the "goodness" or "badness" of the deck, but also had reportable knowledge that was well placed to facilitate choice (Maia and McClelland, 2004, p. 16078). Maia and McClelland (2004) therefore claimed that participants playing the IGT did have access to explicit awareness about the contingencies of the game. They argued that this resulted from the self-paced nature of the task, which allowed ample time for deliberative reasoning, and also that the outcomes of choices were presented 
in a clear numerical form, which aided explicit tracking and learning of the incentive nature of each deck (at least to some degree - though see Peatfield et al., 2012 above). Thus, Maia and McClelland (2004) posited a degree conscious awareness of the task in participants, albeit of a different form of awareness to that proposed by Bechara et al. (1997). Indeed, this difference was captured by asking participants probing questions about the task, rather than by assessing notoriously difficult-toverbalize and general feeling. Therefore, Maia and McClelland's (2004) quantitative method successfully examined explicit awareness, but failed to tap affectively mediated qualitative knowledge (feelings) about the game that may indeed facilitate favorable choices. Importantly, Maia and McClelland (2004) suggests multiple source of information might possibly guide the choice during complex-decisions.

Further, empirical support on the question of awareness, comes from the work of Bowman et al. (2005). In this study, participants quantitatively rated the "goodness/badness" of each deck after each twenty-card block. Bowman et al.'s (2005) data suggested that participants could explicitly report affective evaluation (i.e., the relative goodness/badness) of the task objects, even during the "pre-hunch" phase (Bechara et al., 1997). In fact, participants showed obvious awareness of the "valence" of the decks, even following the first 20 trials of the task. Other studies (e.g., Evans et al., 2004; Cella et al., 2007) using the same method of tracking task subjective awareness, confirm these original findings, and indeed extend them to a psychiatric population (Evans et al., 2005). However, Turnbull et al. (2007) confirmed, in neurotypicals, that dissociations do occur between explicit deck ratings and behavioral choices on the IGT - suggesting that participants can and do actively ignore explicit knowledge regarding the incentive values of their choices, in favor of implicit emotion-mediated knowledge, especially in situations where varying sources of information come into conflict.

Thus, it appears that explicit (emotion-mediated)-knowledge of incentive values of choice is available much earlier than originally claimed by Bechara et al. (1997). This form of awareness is also a type substantially different in quality to that encountered during explicit cognitive approaches to decision making (Gilhooly and Murphy, 2005). The descriptions of these decisions emphasize the fact that the non-cognitive choices are, in contrast, poorly formed ("a hunch") and laden with affect ("a gut feeling"). It is perhaps this knowledge that subserves the phenomenon that has been long described as "intuition" (see also Kahneman and Tversky, 1973; Stanovich and West, 2000; Kahneman, 2003; Turnbull et al., 2003, 2005).

\section{INTUITION?}

We are therefore faced with an interesting, and under-investigated, phenomenon, whereby humans are aided in navigating complex and uncertain problem-spaces, via the awareness of emotionbased signals - presumably derived from prior experience of objects and/or agents. (Kahneman etal., 1982; see Kahneman, 2003) have long described the properties of such intuitive responses as being fast, rapid, explicit, effortless, and emotionally laden. Stanovich and West (2000) have proposed a similar dichotomy (e.g., Hogarth, 2001; Myers, 2002). Both seek to discriminate between systems underpinning "intuition" versus "reasoning" (Kahneman, 2003). One approach (intuition; or System 1) generates an overall and apparently imprecise general impression of objects or situations, through an involuntary process sometimes described as natural assessment (Tversky and Kahneman, 1983). This phenomenon emerges without intention or effort, and could not (they argued) be verbalized explicitly. In contrast, the reasoning pathway (System 2) is involved when more formal judgements are made, even if these are not overtly expressed (Kahneman, 2003; for more on this in relation to the IGT see Bechara, 2005; Cella et al., 2007; Stocco et al., 2009). However, such reason-based decisions were always intentional and explicit.

"Intuitive" is therefore a label which appears to capture a decision process reflecting imprecise and emotion-based impressions. We have argued that such EBL systems may pre-empt or guide reason-based choice, when faced with settings involving combinations of a complex problem space; high levels of uncertainty and ambiguity; and laden or infused with affect. Interestingly, this literature potentially links to emotion-based systems of the sort found in psychiatric disorders (Evans et al., 2005), or neurological disorders of emotion regulation (Fotopoulou et al., 2004) - where both groups show impaired understanding in the form of delusional beliefs. These affectively laden biases may perhaps appear without conscious awareness, and lack explicit understanding, even when producing successful outcomes (Damasio, 1994, pp. 187-189; Turnbull et al., 2007).

In sum, one form of conscious awareness does appear to be readily achieved during the IGT, but this is in the sense of an emotion-based impression: "How much do I like this object?" (Bowman et al., 2005; Evans et al., 2005), though this may also explain why Bechara et al. (1997) report that optimal IGT decision-making operates outside of formal cognitive scrutiny.

\section{PRE-EXISTING AFFECTIVE BIAS ON THE IGT}

The IGT is usually regarded as a good simulation of the complexity of real-world decision-making, given that it involves exploratory decisions under both risk and ambiguity (e.g., Brand et al., 2007), with shifting contingencies over time. Although other tasks may provide a better psychological dissection of the decision-making processes (e.g., Fellows, 2004; Dunn et al., 2006, 2010; Brand et al., 2007), the IGT is typically regarded as affording an ecologically rich and complex problem space (Damasio et al., 1991; Bechara et al., 1994). Of particular interest is the "balance," or trade-off, between cognition and affect, as a measure of adaptive task performance (e.g., Manes et al., 2002; Fellows and Farah, 2005; Dunn et al., 2006, 2010; Cassotti et al., 2011). For instance, affective states appear to especially underpin adaptive decisions in the early "opaque" and ambiguous period of the IGT, with the latter phase of the task (as discussed above) more readily informed by conscious awareness of the incentive properties (e.g., Maia and McClelland, 2004; Bowman et al., 2005; Dunn et al., 2006; Brand et al., 2007; Wagar and Dixon, 2007; Stocco and Fum, 2008).

What then of the fact that humans are often biased or predisposed - toward objects, even before they first encounter them? And how does this bias shift over time? Notably, the IGT involves an intrinsic affective shift, where initially learned 
associations require reversal for adaptive behavior on the task (Fellows and Farah, 2005). In many ways, such pre-existing affective biases might be regarded as the psychological foundation of prejudice - for example where humans express a pre-existing negative evaluation, in the absence of knowledge of the object's intrinsic properties (e.g., Allport, 1954/1979). Overcoming such biases clearly requires reversal of an affectively laden association. Notably, such social biases are understood to be both common and well-established, with the potential to linger outside full awareness (Devine, 1989; Amodio et al., 2003; Gregg et al., 2006). Indeed, the notion that most objects rapidly and automatically evoke affective states is now well-established (e.g., Zajonc, 1980; LeDoux, 1996; Ito and Urland, 2003; Cunningham et al., 2004). Therefore, an ecologically valid starting point for the IGT would be a set of objects which are affectively laden, rather than neutral.

A relevant distinction, and one often stressed by the social cognition literature, is that affect can be sourced from an evaluation of the features of the target itself (integral affect), or influenced by the background mood state or another unrelated source (incidental affect, Pham etal., 2001; Mussweiler and Bodenhausen, 2002; Finucane et al., 2003). Thus, integral affect may result from actual, perceived, or even imaginary characteristics of the decision targets - i.e., with a focus or the object itself. In contrast, incidental affect is sourced from temporary mood states, trait affective states (e.g., anxiety), or transferred from other diffuse sources distinct from the target object (e.g., Cohen et al., 2008).

How might these sources of affect influence complex decisionmaking? It is likely they are incorporated into an online affective state, which is readily placed to infuse and bias choices (Damasio, 1994; Finucane et al., 2003; Cohen et al., 2008). Here, the literature is patchy in its coverage. The influence of "incidental" affect on judgment and decision-making has been well-studied, suggesting that there are gains in the flexibility and openness of problemsolving in positive mood states (e.g., Isen, 2001), and risk-aversion in states of anxiety (e.g., Raghunathan and Pham, 1999). Indeed, incidental affect appears to have important impacts on IGT performance (Schmitt et al., 1999; Carter and Smith-Pasqualini, 2004; Suhr and Tsandis, 2007). However, the primacy (e.g., Zajonc, 1980; LeDoux, 1996) and importance of integral (object biased) affect for judgement and decision-making has been less well-investigated (Pham etal., 2001; Finucane et al., 2003). Surprisingly, only a few studies (Hinson et al., 2006; Davies and Turnbull, 2011; Aïte et al., 2013) have assessed integral affective bias in decision-making paradigms like the IGT - although questions of this sort are highly relevant for human social decision-making (e.g., Bechara et al., 1994).

Notably, real-world social behavior involves encountering agents and objects that develop, and ultimately come to possess, ambiguous and ambivalent characteristics (e.g., Cacioppo and Berntson, 1994; Cunningham etal., 2003). Thus, an appraisal of a well-known individual (e.g., Tony Blair, Barack Obama, Lance Armstrong, Edward Snowden) may well evoke both negative and positive evaluations, potentially resulting in a net-weighted (heuristic-based) attitude (e.g., Van Harreveld etal., 2004). Ecologically rich paradigms such as the IGT have only recently been employed to examine the impact of affective biases in complex and dynamic decision-making (Hinson etal., 2006; Davies and Turnbull, 2011; Aite et al., 2013). The following section presents an overview of this research.

\section{INSIGHTS FROM TASKS INVOLVING AFFECTIVE BIAS}

Given the proposed primacy of emotion-based processes (Bechara et al., 1994, 1997), it is perhaps surprising that only three studies have examined affective bias within IGT-style decision-making. While each study uses different variants of the IGT, and a range of affective biases, the data are broadly consistent - demonstrating that pre-existing bias readily impacts complex decision-making (Hinson et al., 2006; Davies and Turnbull, 2011; Aïte et al., 2013).

Using a three-deck variant of the IGT, Hinson et al. (2006) invoked affective bias, by associating task decks with emotional words, which varied according to deck incentives. In the incongruent condition, the "good" deck was labeled with negative words, and "bad" deck labeled with positive words (with the associations reversed for the congruent condition). Additionally, a third "neutral" deck was labeled with emotionally neutral words. As one might predict, incongruent affective bias impaired performance, while congruent bias enhanced decision-making. Thus, the use of stable emotional landmarks from the outset of the task readily biased IGT-style decision-making.

The SCR data collected during the experiments (Hinson et al., 2006) were used to examine the development of discriminating anticipatory SCRs. Incongruent affective bias was found to hinder the development of these physiological markers - with little discrimination in differential SCRs across the three decks. However, in the congruent condition, these anticipatory markers appeared to selectively distinguish between bad deck choices from both good and neutral options. These responses are often viewed as an index of decision biasing "somatic markers" (Bechara et al., 1997). However, in this study the somatic signals produced no causal influence on decision behavior, merely acting as one index of adaptive decision-making (Hinson et al., 2006).

Building on these findings, Davies and Turnbull (2011) investigated features of the classic Gambling Task potentially influenced by affective bias - expanding the topic to include features such as sensitivity to punishment cues (Dalgleish et al., 2004), and the dynamic tracking and weighting of overall deck attitudes (e.g., Van Harreveld etal., 2004; Bowman et al., 2005) that were not explored in the Hinson et al. (2006) experiments. The Davies and Turnbull (2011) tasks introduced affective bias using visual stimuli that were either non-social (International Affective Picture System; Lang etal., 2001) or more socially salient, in the form of racially diverse faces (Tottenham et al., 2009). To control for individual variation, the stimuli were also customized for each participant, by pre-evaluation. As in the Hinson et al. (2006) studies, there was a growing preference for selections from the advantageous decks. Importantly, affective bias altered selection in both congruent and incongruent conditions; especially both experiments demonstrated that affective labels impaired selection behavior specifically under incongruent conditions. Additionally, the study (experiment 2) also showed a clear influence of affective bias on subjective ratings of task objects over the task. 
This sparks the question of how such decision-making is changed. Congruency did not influence shifts from the frequently punishing decks, nor did it alter preferences for decks with lower loss frequency. Also, decoupling subjective evaluation data to absolute deck ratings showed that weighting of deck attitudes were unaltered by the congruency manipulation. However, incongruent association selectively modulated evaluation of the disadvantageous decks. Indeed, consolidating the importance of awareness of the affective nature of the punishing bad decks, subjective awareness of their incentive nature was strongly associated with adaptive task performance (cf. Maia and McClelland, 2004; Bowman et al., 2005). Such dissociation between deck ratings suggests that deck attitudes in general were not influenced by affective bias. Instead it appears that sensitivity to accumulating losses is a major driving force in IGT decision-making (Christakou et al., 2009; Weller et al., 2007, 2010; cf. Dunn et al., 2010).

\section{PRE VERSUS POST-DECISIONS}

Both of the above studies (i.e., Hinson et al., 2006; Davies and Turnbull, 2011) introduced affective bias at the decision level. In contrast, a recent study (Aite et al., 2013) suggests that placing affective stimuli during the post-decision (feedback stage) phase of decision-making also affects performance on IGT. Here, the ability to make an advantageous choice increases when the emotional context is congruent with the feedback, while this is impaired in an incongruent condition. Indeed, facial emotion appears to carry intrinsic incentive value (Shore and Heerey, 2011); therefore presenting bias during the feedback phase should modulate the net decision feedback. For example, providing a reward of $\$ 10$ with a smile would provide more positive reinforcement than the same reward with a fearful face.

The findings of Aite et al. (2013) are thus consistent with affective bias influencing the decision process via a range of plausible pathways and mechanisms - both affective and cognitive (e.g., Hinson et al., 2002, 2006; Dunn et al., 2006, 2010). Incongruent affective bias again leads to a robust impact on IGT decisionmaking (cf. Hinson et al., 2006; Davies and Turnbull, 2011). This would be consistent with the observations made by Davies and Turnbull (2011), and further imply that affective bias within IGT variants disrupts adaptive shifting of decision behavior in the face of changing contingencies (i.e., reversal learning).

A notable inference derived from this study surrounds the use of additional supporting feedback the IGT (and other decisionmaking paradigms) often present additional feedback with affective value (e.g., smiley faces). Such feedback probably consolidates reinforcement of primary incentive feedback, potentially complicating task interpretation (Shore and Heerey, 2011). However, as highlighted by Aite et al. (2013), the use of such feedback may be unhelpful methodologically, and should therefore be discouraged in IGT experiments.

In sum, a modest number of studies have manipulated the affective loading of IGT tasks - with positive and negative biases, and pre or post-decision influences. All make it clear that affective labeling has a substantial affect on performance, biasing outcome in the direction of the emotion-based influence. Psychophysiological data showed that anticipatory SCRs did not appear to be an important (or necessary) indicator of good decisions. Finally, the awareness of accumulating loss was found to be critical for adaptive task performance (cf. loss aversion; Weller et al., 2007, 2010). In demonstrating these effects, the studies show a useful analogy for the biases of prejudice in everyday decisionmaking, while demonstrating the flexibility of the IGT as a research tool.

\section{DISSOCIATING EPISODIC MEMORY AND EMOTION-BASED LEARNING}

The remarkably rich literature on the IGT has been a central source of evidence for the role of the frontal lobes in EBL (e.g., Bechara et al., 1994, 1997; Rogers et al., 1999; Bowman and Turnbull, 2004). Indeed, Bechara et al. (1997) original paper especially emphasized the role of ventromedial pre-frontal cortex (VMPFC). A later set of studies narrowed the focus, to investigate which specific frontal regions (right or left, dorsal or lateral, or ventral or medial) played the most significant role in EBL (e.g., Rogers et al., 1999; Duncan and Owen, 2000; see Manes et al., 2002; for a detailed discussion).

However, this focus on the frontal lobes, and thus on executive functions, has potentially ignored the role of other brain areas, and indeed other classes of psychological ability. An especially interesting question is the relationship between EBL and episodic memory. In this section of the paper, we will present evidence from lesion (e.g., Damasio et al., 1996; Bechara et al., 1998; Turnbull and Evans, 2006) and neuroimaging studies (e.g., Patterson et al., 2002; Fukui et al., 2005), to understand the relationship between these key psychological systems.

\section{EMOTION-BASED LEARNING AND EPISODIC MEMORY}

The neurobiology of EBL is far less well understood than that mediating episodic memory. However, an introductory survey of likely brain regions might include a full range of subcortical emotion systems (e.g., Panksepp, 1986, 1998; Davidson and Irwin, 1999; LeDoux, 2000; Rolls, 2000; Calder et al., 2001; Phan etal., 2002; Bechara etal., 2003; Berridge, 2003; Patterson and Schmidt, 2003; Adolphs et al., 2005), as well as the connection between these systems and pre-frontal cortex, in many cases through the VM frontal lobes (Davidson and Irwin, 1999; Bechara etal., 2000a; Bechara, 2004; Anderson etal., 2006).

Consistent with this, studies also suggest that certain emotional-learning processes clearly involve medial prefrontal cortex (e.g., Lane etal., 1997; Reiman etal., 1997). A metaanalysis of neuroimaging studies, for example, suggest that medial prefrontal cortex is involved in emotion-based tasks, while the anterior cingulate and insula are involved when tasks have both emotional and cognitive load (see Phan et al., 2002).

However, lesion-study and imaging findings have suggested that episodic memory systems (Tulving, 1972, 1983) particularly include the medial temporal lobes and associated structures (e.g., Zola-Morgan et al., 1986; McDonald and White, 1993; Schacter et al., 1995; Nyberg et al., 1996; Schacter et al., 1996; Rugg et al., 1997; Clark and Squire, 1998). In principle, if EBL and episodic memory systems are anatomically independent (Tranel and Damasio, 1993) it should be possible to disrupt one system and leave the other intact.

Evidence of such intact EBL has long been reported, notably in a classic patient with amnesia (Claparède, 1951). In this well-known 
report, Claparède concealed a pin in his palm, before shaking the hand of an amnesic patient. On the day following this painful episode, the patient refused to shake the physician's hand, despite having no conscious recollection of the incident (Claparède, 1951; for review see Eichenbaum and Cohen, 2001). Modern and systematic evidence for the claim comes from the work on the profoundly amnesic patient, Boswell (Tranel and Damasio, 1990, 1993; Feinstein et al., 2010). In the experiment (Tranel and Damasio, 1993), Boswell engaged in inter-personal encounters with stooges who played a "good," "neutral," or "bad" character in their interactions. After a week, Boswell was shown sets of photographs that included the face of one of the individuals, and an unfamiliar face, and was asked to "Pick the person you would like best?" (p. 83). Naturally, Boswell had no explicit memory of any of the individuals (tested with a free or cued recall). However, when asked to make a forcedchoice response, Boswell chose the "good" character almost $80 \%$ of the time, and virtually never chose the bad character (Tranel and Damasio, 1993).

What of complex learning tasks that also have a reward-based element? Interestingly, some studies have reported relatively normal performance by amnesic patients on the Wisconsin Card Sorting Test (WCST; e.g., Leng and Parkin, 1988; Shoqeirat et al., 1990), and the probabilistic "Weather Prediction" Task (WPT; Knowlton et al., 1994, 1996). A plausible hypothesis is that these tasks also have an emotion-based preference - given that the experimenter provides "correct" or "incorrect" feedback after each trial.

\section{COMPLEX EMOTION-BASED LEARNING}

Empirical evidence from such studies (see also Johnson et al., 1985; Tranel and Damasio, 1989, 1990, 1993) thus suggests that capacity to learn complex emotional valence may be retained in profoundly amnesic patients. However, many of reports of the sort described above relate to relatively simple patterns of emotional valence learning (uniformly good versus uniformly bad, e.g., Tranel and Damasio, 1993; Feinstein etal., 2010), rather than the more sophisticated patterns of valence which characterize everyday life (e.g., Barraclough et al., 2004). As noted earlier, it is precisely this complicated pattern of reward and punishment that the IGT was designed to assess (Bechara et al., 2000a).

In this context, Turnbull and Evans (2006) measured the IGT performance of a profoundly amnesic patient (SL) who had suffered a posterior cerebral artery stroke, producing profound amnesia. On the IGT, SL performed at a comparable level to controls, across a 3-week period, where each week his performance was no different to (or in one case much better), than controls. This learning was also seen despite the fact that the reward-contingency pattern was shifted between sessions (c.f. Fellows and Farah, 2003), and that SL was unable to explicitly recall any aspect of the previous sessions, or recognize the examiner - evidence suggesting that EBL was preserved.

Thus, complex EBL can remain intact despite profound amnesia - though this effect is not universal. Turnbull and Evans (2006) patient may have been a relatively rare example of such a powerful dissociation. Gutbrod et al. (2006) report patients with lesions to the basal forebrain $(N=5)$ or medial temporal lobe $(N=6)$ who performed the IGT. Here two patients did develop a behavioral preference, though the other nine patients performance remained at chance. In a further study, Gupta et al. (2009) investigated five patients who had bilateral hippocampal damage, and reported that no patients developed a preference for advantageous over disadvantageous choice.

Further evidence of preserved implicit EBL has been reported in patients with Alzheimer's disease (AD), another pathology targeting the medial temporal lobe (e.g., Winograd et al., 1999; Blessing et al., 2006). For example, Evans-Roberts and Turnbull (2011) investigated EBL using the IGT in a patient with dementia of the Alzheimer's type - who had profound impairment of both verbal and visual recent episodic memory, and completed the Gambling task over three weeks (as in Turnbull and Evans, 2006). Mr. A again performed consistently above chance, an effect which seems unlikely to be a result if the more "liberal" response bias of Alzheimer's patients (Budson et al., 2006).

An interesting related finding was the remarkably good performance, in SL's recognition of paired-associate items (Turnbull and Evans, 2006). He had comprehensively failed to bring even a single one of these pairs to conscious recall on any his 40 previous exposures to the pairs, but nevertheless appeared to have encoded at least some aspect of a memorial linkage between them. One explanation might be that he had stored some emotional marker associated with each pair ("rose-bag," good; "elephantglass," bad). Another possibility might be that the previously tested items had acquired some positive emotional valence through the "mere-exposure" effect (Zajonc, 1980; see Turnbull and Evans, 2006 for detailed report of SL).

These data support the growing evidence that there are multiple memory systems in the brain, especially supporting an anatomical and functional dissociation between episodic (e.g., Schacter and Tulving, 1994; Schacter et al., 2000) and emotion-based memory (Tranel and Damasio, 1993; Damasio, 1994; Panksepp, 1998; see Eichenbaum and Cohen, 2001; Phan et al., 2002 for reviews). These findings are consistent with performance of amnestic patients in other non-declarative memory and learning system (e.g., motor learning). The evidence clearly suggests that EBL systems appear to encode more sophisticated patterns of valence learning than have previously been reported, and sustain these over substantial periods of time, especially in patients with "hippocampal" amnesia (Turnbull and Evans, 2006).

\section{CLINICAL IMPLICATIONS}

These findings have a range of potentially important clinical implications. For example the Evans-Roberts and Turnbull (2011) study on preserved EBL in dementia clearly supports claims from the "person-centered" literature (e.g., Kitwood, 1997; Sabat and Collins, 1999) - that in spite of progressive memory loss (Blessing et al., 2006) patients with $\mathrm{AD}$ are able to learn and retain emotion-based knowledge. Unfortunately, the behavior of many of those who care for patients with AD is less than optimal (Sabat and Collins, 1999). Such carers may hold the opinion that they can perhaps speak critically of such patients, because they will inevitably forget the experience. The systematic findings reported above suggest that patients with $\mathrm{AD}$ may retain emotion-based memories, which may have direct impact on interpersonal relationships with 
patients with memory loss, both in a personal and therapeutic context.

In addition, the finding of preserved emotional learning in the face of profound amnesia is of some interest in the context of infantile amnesia. It is well established that humans have poor, or non-existent, episodic memory for the first few years of life (Freud, 1905; Dudycha and Dudycha, 1941; Sheingold and Tenney, 1982 for review see Pillemer and White, 1989). Indeed, there is some consensus that the earliest adult autobiographical memories are for events that occurred between 2.5 and 4 years of age (Waldfogel, 1948; Wetzler and Sweeney, 1986; Bruce et al., 2000; MacDonald et al., 2000).

Some researchers posit that language development plays a crucial causal role in such childhood amnesia (Allport, 1937; Schachtel, 1947; Simcock and Hayne, 2002; see also Hayne, 2004 for a review). While, modern neuroscientific accounts of the phenomenon stress especially the late development of hippocampal (conscious) memory systems (for further discussion, see Yovell, 2000; see also Jacobs and Nadel, 1985; Turnbull and Evans, 2006). However, surely these children are learning from this period of early childhood? It is now clear that infants do process a well-developed capacity for learning of emotional valence in relation to objects, for example, the quality of attachment relationships with specific adults (Winnicott, 1960; Bowlby, 1969; Ainsworth et al., 1978; Ainsworth, 1985; Fonagy et al., 1991a,b). The empirical evidence from childhood amnesia studies suggests EBL systems might be available to infants possibly much before the hippocampus-based systems develop.

Interestingly, this issue may also be important for our understanding of the mechanisms of psychotherapy. It has been suggested that aspects of the therapeutic alliance might (for example) be mediated by emotion-based non-episodic memory systems (Turnbull et al., 2006). In principle, this topic could be investigated through the study of neurological patients with amnesia in a psychotherapeutic setting (Turnbull et al., 2006). In a report of a patient with severe and stable amnesia, Mr. N (see Kaplan, 1994, pp. 590-624 for details), there is at least some evidence that the patient shows therapeutic gains from the interaction with the therapist (Turnbull et al., 2006). Moore et al. (2012) report a similar finding. These preliminary data suggest that during psychotherapy the interpersonal properties of the therapeutic relationship may still exist in patients with profound amnesia, suggesting that the therapeutic alliance may be mediated by a class of memory system that is separate to that of episodic recall.

\section{CONCLUSION}

Summarizing the literature over the last two decades, it is evident that EBL, in the face of a complex ambiguous decision-making landscape, is an important psychological process that occurs rapidly, and is remarkably flexible. This specific form of learning contributes to the scientific understanding of psychological phenomena such as intuition, prejudice that were long ignored, and often difficult to define functionally.

For much of its history, psychological science focused on rational choice, rather that the less well-specified and emotionbased intuitive aspects of human choice (Gilhooly and Murphy, 2005). These later systems are clearly enormously important for human beings, and this paper has reviewed our growing understanding of range of important issues: the flexibility of theses systems, their access to conscious awareness, their relationship to episodic memory, their role in prejudice, and a number of potentially important implications for psychotherapy and care of the elderly. However, this strand of research is clearly still only in the early stages of development, and we anticipate a range of future discoveries on this scientifically important topic.

\section{REFERENCES}

Adolphs, R., Tranel, D., and Buchanan, T. W. (2005). Amygdala damage impairs emotional memory for gist but not details of complex stimuli. Nat. Neurosci. 8, 512-518. doi: 10.1038/nn1489

Ainsworth, M. D. S. (1985). Attachments across the life- span. Bull. N. Y. Acad. Med. $61,792-812$

Ainsworth, M. D. S., Blehar, M. C., Waters, E., and Wall, S. (1978). Patterns of Attachment: A Psychological Study of the Strange Situation. Hillsdale, NJ: Lawrence Erlbaum.

Aïte, A., Borst, G., Moutier, S., Varescon, I., Brown, I., Houdé, O., et al. (2013). Impact of emotional context congruency on decision making under ambiguity. Emotion 13, 177-82. doi 10.1037/a0031345

Allport, G. W. (1937). Personality: A Psychological Interpretation. New York: Holt. Allport, G. W. (1954/1979). The Nature of Prejudice. Cambridge, MA: Perseus Books. Amodio, D. M., Devine, P. G., and Harmon-Jones, E. (2003). Individual differences in the activation and control of affective race bias as assessed by startle eyeblink responses and self-report. J. Pers. Soc. Psychol. 84, 738-753. doi: 10.1037/00223514.84.4.738

Anderson, S. W., Barrash, J., Bechara, A., and Tranel, D. (2006). Impairments of emotion and real-world complex behaviour following childhood- or adult-onset J. Int. Neuropsychol. Soc. 12, 224-235. doi: 10.1017/S13556177060 60346

Barraclough, D. J., Conroy, M. L., and Lee, D. (2004). Prefrontal cortex and decision making in a mixed strategy game. Nat. Neurosci. 7, 404-410.

Bechara, A. (2004). The role of emotion in decision-making: evidence from neurological patients with orbitofrontal damage. Brain Cogn. 55, 30-40. doi: 10.1016/j.bandc.2003.04.001

Bechara, A. (2005). Decision making, impulse control and loss of will power to resist drugs: a neurocognitive perspective. Nat. Neurosci. 8, 1458-1463. doi: $10.1038 / \mathrm{nn} 1584$

Bechara, A., Damasio, A. R., Damasio, H., and Anderson, S. W. (1994). Insentivity to future consequences following damage to human prefrontal cortex. Cognition 50, 7-15. doi: 10.1016/0010-0277(94)90018-3

Bechara, A., Damasio, H., and Damasio, A. R. (2000a). Emotion, decision making and the orbito frontal cortex. Cereb. Cortex 10, 295-307. doi: 10.1093/cercor/10.3.295

Bechara, A., Tranel, D., and Damasio, H. (2000b). Characterization of the decisionmaking deficit of patients with ventromedial prefrontal cortex lesions. Brain 123, 2189-2202. doi: 10.1093/brain/123.11.2189

Bechara, A., Damasio, H., and Damasio, A. R. (2003). Role of the amygdala in decision-making. Ann. N. Y. Acad. Sci. 985, 356-369. doi: 10.1111/j.17496632.2003.tb07094.x

Bechara, A., Damasio, H., Damasio, A. R., and Lee, G. P. (1999). Different contributions of the human amygdala and ventromedial prefrontal cortex to decision-making. J. Neurosci. 19, 5473-5481.

Bechara, A., Damasio, H., Tranel, D., and Anderson, S. W. (1998). Dissociation of working memory from decision making within the human prefrontal cortex. J. Neurosci. 18, 428-437.

Bechara, A., Damasio, H., Tranel, D., and Damasio, A. R. (1997). Deciding advantageously before knowing the advantageous strategy. Science 275, 1293-1294. doi: 10.1126/science.275.5304.1293

Bechara, A., Tranel, D., Damasio, H., and Damasio, A. R. (1996). Failure to respond autonomically to anticipated future outcomes following damage to prefrontal cortex. Cereb. Cortex 6, 215-225. doi: 10.1093/cercor/6.2.215

Berridge, K. C. (2003). Pleasures of the brain. Brain Cogn. 52, 106-128. doi: $10.1016 /$ S0278-2626(03)00014-9 
Blair, R. J. R., Colledge, E., and Mitchell, D. G. V. (2001). Somatic markers and response reversal: is there orbitofrontal cortex dysfunction in boys with psychopathic tendencies? J. Abnorm. Child Psychol. 29, 499-511. doi: 10.1023/A:1012277125119

Blessing, A., Keil, A., Linden, D. E. J., Heim, S., and Ray, W. J. (2006). Acquisition of affective dispositions in dementia patients. Neuropsychologia 44, 2366-2373. doi 10.1016/j.neuropsychologia.2006.05.004

Bowlby, J. (1969). Attachment and Loss, Vol. 1, Attachment. New York: Basic Books.

Bowman, C. H., and Turnbull, O. H. (2004). Emotion-based learning on a simplified card task: the Iowa and Bangor Gambling tasks. Brain Cogn. 53, 277-282. doi: 10.1016/j.bandc.2004.02.009

Bowman, C. H., Evans, C. E. Y., and Turnbull, O. H. (2005). Artificial time-constraints on the Iowa Gambling Task: the effects on behavioural performance and subjective experience. Brain Cogn. 57, 21-25. doi: 10.1016/j.bandc.2004.08.015

Brand, M., Recknor, E. C., Grabenhorst, F., and Bechara, A. (2007). Decisions under ambiguity and decisions under risk: correlations with executive functions and comparisons of two different gambling tasks with implicit and explicit rules. $J$. Clin. Exp. Neuropsychol. 29, 86-99. doi: 10.1080/13803390500507196

Bruce, D., Dolan, A., and Phillips-Grant, K. (2000). On the transition from childhood amnesiato the recall of personal memories. Psychol. Sci. 11, 360-364. doi: 10.1111/1467-9280.00271

Budson, A. E., Wolk, D. A., Chong, H., and Waring, J. D. (2006). Episodic memory in Alzheimer's disease: separating response bias from discrimination. Neuropsychologia 44, 2222-2232. doi: 10.1016/j.neuropsychologia.2006.05.024

Cacioppo, J. T., and Berntson, G. G. (1994). Relationship between attitudes and evaluative space: a critical review, with emphasis on the separability of positive and negative substrates. Psychol. Bull. 115, 401-423. doi: 10.1037/00332909.115.3.401

Calder, A. J., Lawrence, A. D., and Young, A. W. (2001). Neuropsychology of fear and loathing. Nat. Rev. Neurosci. 2, 352-363. doi: 10.1038/35072584

Carter, S., and Smith-Pasqualini, M. C. (2004). Stronger autonomic response accompanies better learning: a test of Damasio's somatic marker hypothesis. Cogn. Emot. 18, 901-911. doi: 10.1080/02699930341000338

Cassotti, M., Houdé, O., and Moutier, S. (2011). Developmental changes of win-stay and loss-shift strategies in decision making. Child Neuropsychol. 17, 400-411. doi: 10.1080/09297049.2010.547463

Cavedini, P., Riboldi, G., D’Annucci, A., Belotti, P., Cisima, M., and Bellodi, L. (2002). Decision-making heterogeneity in obsessive- compulsive disorder: ventromedial prefrontal cortex function predicts different treatment outcomes. Neuropsychologia 40, 205-211. doi: 10.1016/S0028-3932(01)00077-X

Cella, M., Dymond, S., Cooper, A., and Turnbull, O. (2007). Effects of decisionphase time constraints on emotion-based learning in the Iowa Gambling Task. Brain Cogn. 64, 164-169. doi: 10.1016/j.bandc.2007.02.003

Christakou, A., Brammer, M., Giampietro, V., and Rubia, K. (2009). Right ventromedial and dorsolateral prefrontal cortices mediate adaptive decisions under ambiguity by integrating choice utility and outcome evaluation. J. Neurosci. 29, 11020-11028. doi: 10.1523/JNEUROSCI.1279-09.2009

Claparède, E. (1951). "Recognition and "me"ness," in Organisation and Pathology of Thought, ed. D. Rapaport (New York: Columbia University Press), 58-75. (Reprinted from Archives de Psychologies, 11, 79-90, by E. Claparade, ed. 1911).

Clark, L., Bechara, A., Damasio, H., Aitken, M. R. F., Sahakian, B. J., and Robbins, T. W. (2008). Differential effects of insula and ventromedial prefrontal cortex lesions on risky decision-making. Brain 131, 1311-1322. doi: 10.1093/brain/ awn066

Clark, R. E., and Squire, L. R. (1998). Classical conditioning and brain systems: the role of awareness. Science 280, 77-81. doi: 10.1126/science.280.5360.77

Cohen, J. B., Pham, M. T., and Andrade, E. B. (2008). "The nature and role of affect in consumer behaviour," in Handbook of Consumer Psychology, eds C. P. Haugtvedt, P. Herr, and F. Kardes (Mahwah, NJ: Lawrence Erlbaum), 297-348.

Cunningham, W. A., Johnson, M. K., Gatenby, J. C., Gore, J. C., and Banaji, M. R. (2003). Neural components of social evaluation. J. Pers. Soc. Psychol. 85, 639-649. doi: 10.1037/0022-3514.85.4.639

Cunningham, W. A., Johnson, M. K., Raye, C. L., Gatenby, J. C., Gore, J. C., and Banaji, M. R. (2004). Separable neural components in the processing of black and white faces. Psychol. Sci. 15, 806-813. doi: 10.1111/j.0956-7976.2004.00760.x

Dalgleish, T., Yiend, J., Bramham, J., Teasdale, J. D., Ogilvie, A. D., Malhi, G., et al. (2004). Neuropsychological processing associated with recovery from depression after stereotactic subcaudate tractotomy. Am. J. Psychiatry 161, 1913-1916. doi: 10.1176/appi.ajp.161.10.1913

Damasio, A. (1994). Descartes' Error: Emotion, Reason and the Human Brain. NewYork: Putnam.

Damasio, A. R. (1989a). The brain binds entities and events by multiregional activation from convergence zones. Neural Comput. 1, 123-132. doi: 10.1162/neco.1989.1.1.123

Damasio, A. R. (1989b). Time-locked multiregional retroactivation: a systems-level proposal for the neural substrates of recall and recognition. Cognition 33, 25-62. doi: 10.1016/0010-0277(89)90005-X

Damasio, A. R., Everitt, B. J., and Bishop, D. (1996). The somatic marker hypothesis and the possible functions of the prefrontal cortex. Philos. Trans. R. Soc. B Biol. Sci. 351, 1413-1420. doi: 10.1098/rstb.1996.0125

Damasio, A. R., Tranel, D., and Damasio, H. (1991). "Somatic markers and the guidance of behaviour: theory and preliminary testing," in Frontal Lobe Function and Dysfunction, eds H. S. Levin, H. M. Eisenberg, and A. L. Benton (New York: Oxford University Press), 217-229.

Davidson, R. J., and Irwin, W. (1999). The functional neuroanatomy of emotion and affective style. Trends Cogn. Sci. 3, 11-21. doi: 10.1016/S1364-6613(98)01265-0

Davies, J. L., and Turnbull, O. H. (2011). Affective bias in complex decision making: modulating sensitivity to aversive feedback. Motiv. Emot. 35, 235-248. doi: 10.1007/s11031-011-9217-x

Devine, P. G. (1989). Stereotypes and prejudice: their automatic and controlled components. J. Pers. Soc. Psychol. 56, 5-18. doi: 10.1037/0022-3514.56.1.5

Dudycha, G. J., and Dudycha, M. M. (1941). Childhood memories: a review of the literature. Psychol. Bull. 38, 668-682. doi: 10.1037/h0055678

Duncan, J., and Owen, A. M. (2000). Common regions of the human frontal lobe recruited by diverse cognitive demands. Trends Neurosci. 23, 475-483. doi: 10.1016/S0166-2236(00)01633-7

Dunn, B. D., Dalgleish, T., and Lawrence, A. D. (2006). The somatic marker hypothesis: a critical evaluation. Neurosci. Biobehav. Rev. 30, 239-271. doi: 10.1016/j.neubiorev.2005.07.001

Dunn, B. D., Makarova, D., Evans, D., and Clark, L. (2010). "I'm worth more than that": trait positivity predicts increased rejection of unfair financial offers. PLoS ONE 5:e15095. doi: 10.1371/journal.pone.0015095

Eichenbaum H., and Cohen, N. J. (2001). From Conditioning to Conscious Recollection: Memory Systems of the Brain. New York: Oxford University Press.

Evans, C. E. Y., Kemish, K., and Turnbull, O. H. (2004). Paradoxical effects of education on the Iowa Gambing Task. Brain Cogn. 54, 240-244. doi: 10.1016/j.bandc.2004.02.022

Evans, C. Y., Bowman, C. H., and Turnbull, O. H. (2005). Subjective awareness on the Iowa Gambling Task: the key role of emotional experience in schizophrenia. J. Clin. Exp. Neuropsychol. 27, 656-664. doi: 10.1081/13803390490918354

Evans-Roberts, C. E. Y., and Turnbull, O. H. (2011). Remembering relationships: preserved emotion-based learning in Alzheimer's disease. Exp. Aging Res. 31, 1-16. doi: 10.1080/0361073X.2011.536750

Feinstein, J. S., Duff, M. C., and Tranel, D. (2010). Sustained experience of emotion after loss of memory in patients with amnesia. Proc. Nat. Acad. Sci. U.S.A. 107, 7674-7679. doi: 10.1073/pnas.0914054107

Fellows, L. K. (2004). The cognitive neuroscience of human decision making: a review and conceptual framework. Behav. Cogn. Neurosci. Rev. 3, 159-172. doi: $10.1177 / 1534582304273251$

Fellows, L. K., and Farah, M. (2003). Ventromedial frontal cortex mediates affective shifting in humans: evidence from a reversal learning paradigm. Brain 126, 1830 1837. doi: 10.1093/brain/awg180

Fellows, L. K., and Farah, M. J. (2005). Different underlying impairments in decision-making following ventromedial and dorsolateral frontal lobe damage in humans. Cereb. Cortex 15, 58-63. doi: 10.1093/cercor/bhh108

Finucane, M. L., Peters, E., and Slovic, P. (2003). "Judgment and decision making: the dance of affect and reason," in Emerging Perspectives on Decision Research, eds S. L. Schneider and J. Shanteau (New York: Cambridge University Press), 327-364.

Fonagy, P., Steele, H., Moran, G., Steele, M., and Higgitt, A. (1991a). The capacity for understanding mental states: the reflective self in parent and child and its significance for security of attachment. Inf. Mental Health J. 13, 200-217. doi: 10.1002/1097-0355(199123)12:33.0.CO;2-7

Fonagy, P., Steele, H., and Steele, M. (1991b). Maternal representations of attachment during pregnancy predict the organization of infant-mother attachment at one year of age. Child Dev. 62, 891-905. doi: 10.2307/1131141 
Fotopoulou, A., Solms, M., and Turnbull, O. H. (2004). Wishful reality distortions in confabulation: a case report. Neuropsychologia 47, 727-744. doi: 10.1016/j.neuropsychologia.2003.11.008

Freud, S. (1905). Three Essays on the Theory of Sexuality, Standard Edition. 7, 125-243.

Fukui, H., Murai, T., Fukuyama, H., Hayashi, T., and Hanakawa, T. (2005). Functional activity related to risk anticipation during performance of the Iowa Gambling Task. Neuroimage 24, 253-259. doi: 10.1016/j.neuroimage.2004. 08.028

Gigerenzer, G. (2004). "Fast and frugal heuristics: the tools of bounded rationality," in Blackwell Handbook of Judgment and Decision Making, eds D. Koehler and N. Harvey (Oxford, UK: Blackwell), 62-88. doi: 10.1002/9780470752937.ch4

Gilhooly, K., and Murphy, P. (2005). Differentiating insight from non-insight problems. Think. Reason. 11,279-302. doi: 10.1080/13546780442000187

Gregg, A. P., Seibt, B., and Banaji, M. A. (2006). Easier done than undone: asymmetry in the malleability of automatic preferences. J. Pers. Soc. Psychol. 90, 1-20. doi: 10.1037/0022-3514.90.1.1

Gupta, R., Duff, M. C., Denburg, N. L., Cohen, N. J., Bechara, A., and Tranel, D. (2009). Declarative memory is critical for sustained advantageous complex decision-making. Neuropsychologia 47, 1686-1693. doi: 10.1016/j.neuropsychologia.2009.02.007

Gutbrod, K., Krouzel, C., Hofer, H., Muri, R., Perrig, W., and Ptak, R. (2006). Decision-making in amnesia: do advantageous decisions require conscious knowledge of previous behavioural choices? Neuropsychologia 44, 1315-1324. doi: 10.1016/i.neuropsychologia.2006.01.014

Happaney, K., Zelazo, P. D., and Stuss, D. T. (2004). Development of orbitofrontal function: current themes and future directions. Brain Cogn. 55, 1-10. doi: 10.1016/j.bandc.2004.01.001

Hayne, H. (2004). Infant memory development: implications for childhood amnesia. Dev. Rev. 24, 33-73. doi: 10.1016/j.dr.2003.09.007

Hinson, J. M., Jameson, T. L., and Whitney, P. (2002). Somatic markers, working memory, and decision making. Cogn. Behav. Affect. Neurosci. 2, 341-353. doi: 10.3758/CABN.2.4.341

Hinson, J. M., Whitney, P., Holben, H., and Wirick, A. K. (2006). Affective biasing of choices in gambling task decision making. Cogn. Affect. Behav. Neurosci. 6 190-200. doi: 10.3758/CABN.6.3.190

Hogarth, R. M. (2001). Educating Intuition. Chicago: University of Chicago Press.

Isen, A. M. (2001). An influence of positive effect on decision making in complex situations: theoretical issues with practical implications. J. Consum. Psychol. 11, 75-85. doi: 10.1207/S15327663JCP1102_01

Ito, T. A., and Urland, G. R. (2003). Race and gender on the brain: electrocortical measures of attention to the race and gender of multiply categorizable individuals. J. Pers. Soc. Psychol. 85, 616-626. doi: 10.1037/0022-3514.85.4.616

Jacobs, W. J., and Nadel, L. (1985). Stress-induced recovery of fears and phobias. Psychol. Rev. 92, 512-531. doi: 10.1037/0033-295X.92.4.512

Johnson, M. K., Kim, J. K., and Risse, G. (1985).Do alcoholic Korsakoffs syndrome patients acquire affective reactions? J. Exp. Psychol. Learn. Mem. Cogn. 11, 22-36. doi: 10.1037/0278-7393.11.1.22

Kahneman, D. (2003). A perspective on judgement and choice. Am. Psychol. 58, 697-720. doi: 10.1037/0003-066X.58.9.697

Kahneman, D., Slovic, P., and Tversky, A. (1982). Judgement Under Uncertainty: Heuristic and Biases. New York: Cambridge University Press.

Kahneman, D., and Tversky, A. (1973). On the psychology of prediction. Psychol. Rev. 80, 237-25l. doi: 10.1037/h0034747

Kaplan, K. L. (1994). Psychoanalytic Aspects of Personality, Emotion and Motivation after Localized Damage. Unpublished doctoral dissertation, University of the Witwatersrand, Johannesburg.

Kitwood, T. (1997). The experience of dementia. Aging Ment. Health 1, 13-22. doi: $10.1080 / 13607869757344$

Knowlton, B., Mangels, J., and Squire, L. (1996). A neostriatal habit learning system in humans. Science 273, 1399-1402. doi: 10.1126/science.273.5280.1399

Knowlton, B. J., Squire, L. R., and Gluck, M. A. (1994). Probabilistic classification learning in amnesia. Learn. Mem. 1, 106-120.

Lane, R. D., Reiman, E. M., Bradley, M. M., Lang, P. J., Ahern, G. L., Davidson, R. J., et al. (1997). Neuroanatomical correlates of pleasant and unpleasant emotion. Neuropsychologia 35, 1437-1444. doi: 10.1016/S0028-3932(97)00070-5

Lang, P. J., Bradley, M. M., and Cuthbert, B. N. (2001). International Affective Picture System (IAPS): Instruction Manual and affective ratings. Technical Report
A-5. Gainesville, FL: The Center for Research in Psychophysiology, University of Florida.

LeDoux, J. E. (1996). The Emotional Brain. New York: Simon \& Schuster.

LeDoux, J. E. (2000). Emotion circuits in the brain. Annu. Rev. Neurosci. 23, 155-184. doi: 10.1146/annurev.neuro.23.1.155

Leng, N. R. C., and Parkin, A. J. (1988). Amnesic patients can benefit from instruction to use imagery: evidence against the cognitive mediation hypothesis. Cortex 24, 33-39. doi: 10.1016/S0010-9452(88)80015-7

Lezak, M. D., Howieson, D. B., Bigler, E. D., and Tranel, D. (2012). Neuropsychological Assessment. Oxford University Press: USA

MacDonald, S., Uesiliana, K., and Hayne, H. (2000). Cross-cultural differences in childhood amnesia. Memory 8, 365-376. doi: 10.1080/09658210050156822

Maia, T. V., and McClelland, J. L. (2004). A re-examination of the evidence for the somaticmarker hypothesis: what participants really know in the Iowa Gambling Task. Proc. Nat. Acad. Sci. U.S.A. 101, 16075-16080. doi: 10.1073/pnas.0406666101

Manes, F., Sahakian, B., Clark, L., Rogers, R., Antoun, N., Aitken, M., et al. (2002). Decision-making processes following damage to the prefrontal cortex. Brain 125, 624-639. doi: 10.1093/brain/awf049

McDonald, R. J., and White, N. M. (1993). A triple dissociation of memory systems: hippocampus, amygdala, and dorsal striatum. Behav. Neurosci. 107, 3-22. doi: 10.1037/0735-7044.107.1.3

Moore, P., Dockree, S., Salas, C., and Turnbull, O. H. (2012). Observations on working psychoanalytically with a profoundly amnestic patient. Paper Presented at the 12th International Neuro-psychoanalysis Society: Congress. Abstract published in Neuro-psychonalysis 14, 240.

Mussweiler, T., and Bodenhausen, G. V. (2002). I know you are, but what am I? Self-evaluative consequences of judging ingroup and outgroup members. J. Pers. Soc. Psychol. 82, 19-32. doi: 10.1037/0022-3514.82.1.19

Must, A., Szabó, Z., Bódi, N., Szász, A., Janka, Z., and Kéri, S. (2006). Sensitivity to reward and punishment and the prefrontal cortex in major depression. J. Affect. Disord. 90, 209-215. doi: 10.1016/j.jad.2005.12.005

Myers, D. G. (2002). Intuition: Its Powers and Perils. New Haven, CT: Yale University Press.

North, N. T., and O'Carroll, R. E. (2001). Decision making in patients with spinal cord damage: afferent feedback and the somatic marker hypothesis. Neuropsychologia 39, 521-524. doi: 10.1016/S0028-3932(00)00107-X

Nyberg, L., McIntosh, A. R., Houle, S., Nilsson, L. G., and Tulving, E. (1996). Activation of medial temporal structures during episodic memory retrieval. Nature 380, 715-717. doi: 10.1038/380715a0

Panksepp, J. (1986). “The psychobiology of prosocial behaviours: separation distress, play and altruism," in Altruism and Aggression: Biological and Social Origins, eds C. Zahn-Waxler, E. M. Cummings, and R. Iannotti (Cambridge: Cambridge University Press), 19-57.

Panksepp, J. (1998). Affective Neuroscience: The Foundations of Human and Animal Emotions. Oxford: Oxford University Press.

Patterson, D., and Schmidt, L. A. (2003). Neuroanatomy of the human affective system. Brain Cogn. 52, 24-26. doi: 10.1016/S0278-2626(03)00005-8

Patterson, J. C., Ungerleider, L. G., and Bandettini, P. A. (2002). Taskindependent functional brain activity correlation with skin conductance changes: an fMRI study. Neuroimage 17, 1797-1806. doi: 10.1006/nimg.2002. 1306

Peatfield, N. A., Turnbull, O. H., Parkinson, J., and Intriligator, J. (2012) Quick as a BLINK: an ultrarapid analogue of Iowa Gambling Task decision making. J. Clin. Exp. Neuropsychol. 34, 243-255. doi: 10.1080/13803395.2011. 633496

Pham, M. T., Cohen, J. B., Pracejus, J. W., and Hughes, G. D. (2001). Affect monitoring and the primacy of feelings in judgement. J. Consum. Res. 28, 167-188. doi: 10.1080/13803395.2011.633496

Phan, K. L., Wager, T., Taylor, S. F., and Liberzon, I. (2002). Functional neuroanatomy of emotion: a meta-analysis of emotion activation studies in PET and fMRI. Neuroimage 16, 331-348. doi: 10.1006/nimg.2002.1087

Pillemer, D. B., and White, S. H. (1989). "Childhood events recalled by children and adults," in Advances in Child Development and Behaviour, Vol. 21, ed. H. W. Reese (Orlando, FL: Academic Press), 297-340.

Raghunathan, R., and Pham, M. T. (1999). All negative moods are not equal: Motivational influences of anxiety and sadness on decision making. Organ. Behav Hum. Decis. Process. 79, 56-77. doi: 10.1006/obhd.1999.2838 
Reiman, E. M., Lane, R. D., Ahern, G. L., Schwartz, G. E., Davidson, R. J., Friston, K. J., et al. (1997). Neuroanatomical correlates of externally and internally generated human emotion. Am. J. Psychiatry 154, 918-925.

Rogers, R. D., Owen, A. M., Middleton, H. C., Williams, E. J., Pickard, J. D., Sahakian, B. J., et al. (1999). Choosing between small, likely rewards and large, unlikely rewards activates inferior and orbital prefrontal cortex. J. Neurosci. 20, 9029-9038.

Rolls, E. T. (2000). Precis of the brain and emotion. Behav. Brain Sci. 23, 177-234. doi: 10.1017/S0140525X00002429

Rolls, E. T., Hornack, J., Wade, D., and McGrath, J. (1994). Emotion related learning in patients with social and emotional changes associated with frontal lobe damage. J. Neurol. Neurosurg. Psychiatry 57, 1518-1524. doi: 10.1136/jnnp. 57.12 .1518

Rugg, M. D., Fletcher, P. C., Frith, C. D., Frackwiak, R. S., and Dolan, R. J. (1997). Brain regions supporting intentional and incidental memory: a PET study. Neuroreport 8, 1283-1287. doi: 10.1097/00001756-199703240-00045

Sabat, S. R., and Collins, M. (1999). Intact social, cognitive ability, and selfhood: a case study of Alzheimer's disease. Am. J. Alzheimers Dis. 14, 11-19. doi: 10.1177/153331759901400108

Schachtel, E. G. (1947). On memory and childhood amnesia. Psychiatry 10, 1-26.

Schacter, D. L., Alpert, N. M., Savage, C. R., Rauch, S. L., and Albert, M. S. (1996). Conscious recollection and the human hippocampal formation: evidence from positron emission tomography. Proc. Natl. Acad. Sci. U.S.A. 93, 321-325. doi: 10.1073/pnas.93.1.321

Schacter, D. L., Reiman, E., Uecker, A., Polster, M. R., Yun, L. S., and Cooper, L. (1995). Brain regions associated with retrieval of structurally coherent visua information. Nature 376, 587-590. doi: 10.1038/376587a0

Schacter, D. L., and Tulving, E. (1994). "What are the memory systems of 1994?," in Memory Systems, eds D. L. Schacter and E. Tulving (Cambridge: MIT Press), $1-38$.

Schacter, D. L., Wagner, A. D., and Buckner, R. L. (2000). “Memory systems of 1999," in The Oxford Handbook of Memory, eds E. Tulving and F. I. M. Craik (New York: Oxford University Press), 627-643.

Schmitt, W. A., Brinkley, C. A., and Newmann, J. P. (1999). Testing Damasio's somatic marker hypothesis with psychopathic individuals: risk takers or risk averse? J. Abnorm. Psychol. 3, 538-543. doi: 10.1037/0021-843X.108.3.538

Sheingold, K., and Tenney, Y. J. (1982). "Memory from a salient childhood event," in Memory Observed, ed. U. Neisser (San Francisco: W. H. Freeman), 201-212.

Shoqeirat, M. A., Mayes, A. R., MacDonald, C., Meudell, P., Pickering, A. (1990). Performance on tests sensitive to frontal lobe lesions by patients with organic amnesia: Leng \& Parkin revisited. Br. J. Clin. Psychol. 29, 401-408. doi: 10.1111/j.2044-8260.1990.tb00903.x

Shore, D. M., and Heerey, E. A. (2011). The value of genuine and polite smiles. Emotion 11, 169-174. doi: 10.1037/a0022601

Simcock, G., and Hayne, H. (2002). Breaking the barrier: children do not translate their preverbal memories into language. Psychol. Sci. 13, 225-231. doi: $10.1111 / 1467-9280.00442$

Stanovich, K. E., and West, R. F. (2000). Individual differences in reasoning: implications for the rationality debate. Behav. Brain Sci. 23, 645-665. doi: 10.1017/S0140525X00003435

Stocco, A., and Fum, D. (2008). Implicit emotional biases in decision making: the case of the Gambling Task. Brain Cogn. 66, 253-259. doi: 10.1016/j.bandc.2007.09.002

Stocco, A., Fum, D., and Napoli, A. (2009). Dissociable processes underlying decisions in the Iowa Gambling Task: a new integrative framework. Behav. Brain Funct. 5, 1. doi: 10.1186/1744-9081-5-1

Suhr, J. A., and Tsanadis, J. (2007). Affect and personality correlates of the Iowa Gambling task. Pers. Individ. Dif. 43, 27-36. doi: 10.1016/j.paid.2006.11.004

Suzuki, A., Hirota, A., Takasawa, N., and Shigemasu, K. (2003). Application of the somatic marker hypothesis to individual differences in decision making. Biol. Psychol. 65, 81-88. doi: 10.1016/S0301-0511(03)00093-0

Tomb, I., Hauser, M., Deldin, P., and Caramazza, A. (2002). Do somatic markers mediate decisions on the gambling task? Nat. Neurosci. 5, 1103-1104. doi: 10.1038/nn1102-1103

Torralva, T., Kipps, C. M., Hodges, J. R., Clark, L., Bekinschtein, T., Roca, M. et al. (2007). The relationship between affective decision-making and theory of mind in the frontal variant of fronto-temporal dementia. Neuropsychologia 45, 342-349. doi: 10.1016/j.neuropsychologia.2006.05.031
Tottenham, N., Tanaka, J. W., Leon, A. C., McCarry, T., Nurse, M., Hare, T. A., et al. (2009). The NimStim set of facial expressions: judgments from untrained research participants. Psychiatry Res. 168, 242-249. doi: 10.1016/j.psychres.2008. 05.006

Tranel, D., and Damasio, A. R. (1990). Covert learning of emotional valence inpatient Boswell. J. Clin. Exp. Neuropsychol. 12, 27.

Tranel, D., and Damasio, A. R. (1993). The covert learning of affective valence does not require structures in hippocampal system or amygdala. J. Cogn. Neurosci. 5, 79-88. doi: 10.1162/jocn.1993.5.1.79

Tranel, D., and Damasio, H. (1989). Intact electrodermal skin conductance responses after bilateral amygdala damage. Neuropsychologia 27, 381-390. doi: 10.1016/0028-3932(89)90046-8

Teuber, H.-L. (1964). “The riddle of frontal lobe function in man," in The Frontal Granular Cortex in Behavior, eds J. M. Warren and K. Akert (New York, NY: McGraw-Hill), 410-444.

Tulving, E. (1972). "Episodic and semantic memory," in Organization Memory, eds E. Tulving and W. Donaldson (New York: Academic Press), 381-403.

Tulving, E. (1983). Ecphoric processes in episodic memory. Philos. Trans. R. Soc. Lond. B Biol. Sci. 302, 361-371. doi: 10.1098/rstb.1983.0060

Tulving, E., and Schacter, D. L. (1990). Priming and human memory systems. Science 247, 301-306. doi: 10.1126/science.2296719

Turnbull, O. H., Berry, H., and Bowman, C. H. (2003). Direct versus indirect emotional consequences on the Iowa Gambling Task. Brain Cogn. 53, 389-392. doi: 10.1016/S0278-2626(03)00151-9

Turnbull, O. H., and Evans, C. E. Y. (2006). Preserved complex emotion-based learning in amnesia. Neuropsychologia 44, 300-306. doi: 10.1016/j.neuropsychologia.2005.04.019

Turnbull, O. H., Evans, C. Y., Bunce, A., Carzolio, B., and O'Connor, J. (2005). Emotion based learning and central executive resources: an investigation of intuition and the Iowa Gambling Task. Brain Cogn. 57, 244-247. doi: 10.1016/j.bandc.2004.08.053

Turnbull, O. H., Worsey, R. B., and Bowman, C. H. (2007). Emotion and intuition: does Schadenfreude make interns poor learners. Philoctetes 1, 5-43.

Turnbull, O. H., Zois, E., Kaplan-Solms, K., and Solms, M. (2006). The developing transference in amnesia: changes in interpersonal relationship, despite profound episodic-memory loss. Neuropsychoanalysis 8, 199-204. doi: 10.1080/15294145.2006.10773530

Tversky, A., and Kahneman, D. (1983). Extensional vs. intuitive reasoning: the conjunction fallacy in probability judgment. Psychol. Rev. 90, 293-315. doi: 10.1037/0033-295X.90.4.293

Van Harreveld, F., Van der Pligt, J., de Vries, N. K., Wenneker, C., and Verhue, D. (2004). Ambivalence and information integration in attitudinal judgement. $\mathrm{Br}$. J. Soc. Psychol. 43, 431-447. doi: 10.1348/0144666042037971

Wagar, B. M., and Dixon, M. (2007). Affective guidance in the Iowa Gambling Task. Cogn. Affect. Behav. Neurosci. 6, 277-290. doi: 10.3758/CABN.6.4.277

Waldfogel, S. (1948). The frequency and affective character of childhood memories. Psychol. Monogr. 62, 1-39. doi: 10.1037/h0093581

Weller J. A., Levin I. P., and Bechara A. (2010). Do individual differences in Iowa Gambling Task performance predict adaptive decision making for risky gains and losses? J. Clin. Exp. Neuropsychol. 32, 141-150. doi: 10.1080/13803390902 881926

Weller, J. A., Levin, I. P., Shiv, B., and Bechara, A. (2007). Neural correlates of adaptive decision making for risky gains and losses. Psychol. Sci. 18, 958. doi: 10.1111/j.1467-9280.2007.02009.x

Wetzler, S. E., and Sweeney, J. A. (1986). "Childhood amnesia: an empirical demonstration,” in Autobiographical Memory, ed. D. C. Rubin (Cambridge, England: Cambridge University Press), 191-201.

Winnicott, D. W. (1960). The theory of the parent-infant relationship. Int. J. Psychoanal. 41, 585-595.

Winograd, E., Goldstein, F. C., Monarch, E. S., Peluso, J. P., and Goldman, W. P. (1999). The mere exposure effect in patients with Alzheimer's disease. Neuropsychology 13, 41-46. doi: 10.1037/0894-4105. 13.1 .41

Yovell, Y. (2000). From hysteria to post traumatic stress dis- order: psychoanalysis and the neurobiology of traumatic memories. Neuro-Psychoanalysis 2, 171-181. doi: 10.1080/15294145.2000.10773303

Zajonc, R. B. (1980). Feeling and thinking: preferences need no inferences. Am. Psychol. 35, 151-175. doi: 10.1037/0003-066X.35.2.151 
Zola-Morgan, S., Squire, L. R., and Amaral, D. G. (1986). Human amnesia and the medial temporal region: enduring memory impairment following a bilateral lesion limited to field cal of the hippocampus. J. Neurosci. 6, 2950-2967. doi: 10.1093/neucas/2.4.259-aw

Conflict of Interest Statement: The authors declare that the research was conducted in the absence of any commercial or financial relationships that could be construed as a potential conflict of interest.

Received: 20 December 2013; accepted: 10 February 2014; published online: 21 March 2014.
Citation: Turnbull OH, Bowman CH, Shanker S and Davies JL (2014) Emotionbased learning: insights from the Iowa Gambling Task. Front. Psychol. 5:162. doi: 10.3389/fpsyg.2014.00162

This article was submitted to Decision Neuroscience, a section of the journal Frontiers in Psychology.

Copyright (c) 2014 Turnbull, Bowman, Shanker and Davies. This is an open-access article distributed under the terms of the Creative Commons Attribution License (CC BY). The use, distribution or reproduction in other forums is permitted, provided the original author(s) or licensor are credited and that the original publication in this journal is cited, in accordance with accepted academic practice. No use, distribution or reproduction is permitted which does not comply with these terms. 